\title{
Efficacy and safety of tigecycline for complicated urinary tract infection: a systematic review
}

\author{
Yang-Xi Liu ${ }^{1 \#}$, Ke-Jia Le ${ }^{1 \#}$, Hong-Yao Shi ${ }^{2 \#}$, Zai-Li Zhang ${ }^{1}$, Min Cui ${ }^{1}$, Han Zhong ${ }^{1}$, Yue-Tian Yu ${ }^{3}$, \\ Zhi-Chun $\mathrm{Gu}^{1}$
}

${ }^{1}$ Department of Pharmacy, Renji Hospital, School of Medicine, Shanghai Jiaotong University, Shanghai, China; ${ }^{2}$ Department of Laboratory Medicine, Shanghai Pubin Children's Hospital, Shanghai, China; ${ }^{3}$ Department of Critical Care Medicine, Renji Hospital, School of Medicine, Shanghai Jiaotong University, Shanghai, China

Contributions: (I) Conception and design: YX Liu, KJ Le; (II) Administrative support: ZC Gu, YT Yu, H Zhong; (III) Provision of study materials or patients: YX Liu, KJ Le; (IV) Collection and assembly of data: YX Liu, KJ Le; (V) Data analysis and interpretation: YX Liu, KJ Le, HY Shi; (VI) Manuscript writing: All authors; (VII) Final approval of manuscript: All authors.

\#These authors contributed equally to this work.

Correspondence to: Han Zhong. Department of Pharmacy, Renji Hospital, School of Medicine, Shanghai Jiaotong University, Shanghai 200127, China. Email: zhonghan@renji.com; Yue-Tian Yu. Department of Critical Care Medicine, Renji Hospital, School of Medicine, Shanghai Jiaotong University, Shanghai 200127, China. Email: fishyyt@sina.com; Zhi-Chun Gu. Department of Pharmacy, Renji Hospital, School of Medicine, Shanghai Jiaotong University, Shanghai 200127, China. Email: guzhichun213@163.com.

Background: Facing the global threat of emerging resistance to antibiotics, tigecycline, a novel glycylcycline antibiotic, is developed to against multidrug-resistant pathogens, but not recommended for the treatment of complicated urinary tract infection (cUTI). We performed a summary of the literatures to characterize and evaluate the efficacy and safety of tigecycline in patients with cUTI.

Methods: We searched PubMed, EMBASE, Cochrane and Clinical Trials using appropriate syntax to retrieve potential articles up to Jan 2020. General information, pathogen, medication regimen, comorbidities of patients from eligible literatures were recorded. Univariate logistic regression analysis was used to detect the potential factors associated with clinical cure.

Results: Nineteen articles comprising 31 cases were included. The subpopulation with transplantation (25.8\% of the patients) was the most common comorbidity, and cUTIs were mainly caused by Klebsiella pneumoniae (K. pneumoniae) (48.28\%) in our research. Tigecycline $100 \mathrm{mg}$ per day as monotherapy was most common. Clinical cure was reported as majority (77.4\%), and microbiological eradication cases accounted for the most (65.2\%) among the clinical cure cases. Univariate analysis showed that $K$. pneumoniae caused cUTI and tigecycline as a single treatment have significant meaning to clinical outcomes $(\mathrm{P}=0.044$ and $\mathrm{P}=0.034$, respectively).

Conclusions: Clinical and microbiological outcomes of tigecycline treatment revealed high rate of successful response. Tigecycline monotherapy may have a role in the treatment of cUTI except that caused by the pathogen $K$. pneumoniae. Further randomized controlled trials was still needed to evaluate tigecycline monotherapy for cUTI.

Keywords: Tigecycline; antibiotics; complicated urinary tract infection (cUTI); Klebsiella pneumoniae (K. pneumoniae); systematic review

Submitted May 30, 2020. Accepted for publication Oct 30, 2020.

doi: $10.21037 /$ tau-20-959

View this article at: http://dx.doi.org/10.21037/tau-20-959 


\section{Introduction}

It is well known that tigecycline, a novel glycylcycline antibiotic with potent antibacterial activity against most multidrug-resistant pathogens such as extended spectrum $\beta$-lactamase (ESBL) positive organisms, carbapenemresistant Enterobacteriaceae (CRE), methicillin-resistant Staphylococcus aureus (MRSA), vancomycin-resistant Enterococcus (VRE), has been approved for the treatment of skin infections, intra-abdominal infections and community-acquired bacterial pneumonia by the United States Food and Drug Administration (FDA), European Medicine Agency (EMA) and National Medical Products Administration (NMPA) (1-3).

With increasing bacterial resistance, antibiotic options for treatment of complicated urinary tract infection (cUTI) caused by multidrug-resistant (MDR) and extensively drugresistant (XDR) organisms are often limited for clinicians. Colistin and aminoglycosides are potential therapeutic options for untreatable gram-negative infections, however, both of those drugs are highly nephrotoxic agents, and acute kidney injury occurs frequently with conventional doses, especially in severe cUTI patients (4).

Although tigecycline is not considered as a valid option for cUTI because of its low serum concentration and limited excretion into urine $(33 \%$ of the total dose is excreted as unchanged tigecycline in urine) (5), several successful cases for the treatment of multidrug-resistant cUTI by tigecycline has been reported in recent years representing tigecycline, as the last-resort drug, become the less toxic option for patients with renal disease $(6,7)$. However, the outcomes of these reports have not been completely consistent. Results of a retrospective cohort study showed no statistically significant differences in microbiologic clearance rates between tigecycline group and untreated group (8). It is hard to demonstrate that tigecycline is as effective in cUTI as in other infections. We therefore summarized and analyzed articles of cUTI patients who were treated with tigecycline to evaluate the efficacy and safety of tigecycline therapy. We present the following article in accordance with the PRISMA reporting checklist (available at http://dx.doi.org/10.21037/tau-20959).

\section{Methods}

This systematic review was established according to the Preferred Reporting Items for Systematic Reviews and Meta-analyses (PRISMA) Statement.

\section{Literature search}

Relevant studies were identified through PubMed, EMBASE, Cochrane and Clinical Trials, all the studies were manually searched from inception to Jan 2020 using the following search syntax: "(tigecycline OR TGC OR tygacil) AND (complicated urinary tract infection OR cUTI OR Urinary infection OR urinary system infection)". Items were searched both in Medical Subject Headings $(\mathrm{MeSH})$ and free text. Language was restricted to English. The reference lists of all articles were reviewed for further identification of potential relevance.

\section{Study selection}

Any study reporting the clinical outcomes of patients with cUTI and receiving tigecycline treatment was considered eligible for inclusion in our study. Two authors (YX Liu and $\mathrm{KJ} \mathrm{Le}$ ) independently reviewed each title and abstract, and assessed full texts of retrieved studies, with any disagreements being resolved via consultation with a third author (H Zhong).

\section{Data extraction}

The following data were extracted from each study: (I) main characteristics of the study (author name, year of publication, and location); (II) main characteristics of the patient (age, gender, sex, comorbidities, type of infection, sepsis or not, and causative pathogen); (III) antibiotic treatment (dose, duration, prior antibiotic therapy, monotherapy or combination therapy); (IV) clinical outcomes (clinical response, microbiological response, recurrence, and total follow-up time). Data were collected by two independent reviewers (YX Liu and KJ Le).

\section{Definition of clinical and microbiological outcomes}

Clinical response was defined as cure (partial or complete improvement of cUTI), failure (no improvement or deterioration of cUTI). Microbiological response was defined as positive (sterile culture results during or at the end of antibiotic therapy), negative (failure to eradicate the organism during or at the end of antibiotic therapy), or not documented.

\section{Statistical analysis}

SPSS 24.0 statistical package (SPSS, Chicago, IL, USA) 


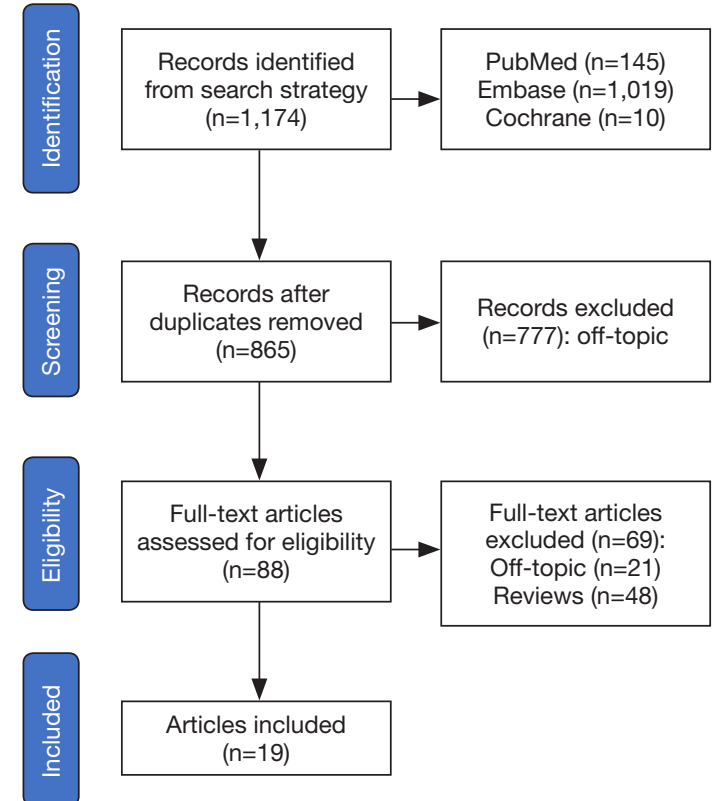

Figure 1 Flow diagram of articles selection. Articles published in PubMed, Embase, Cochrane and Clinical Trials were searched and selected.

was used for data processing and statistical analysis. Student $t$-test was used to evaluate continuous variables and Chisquare test was used to analyze categorical variables. Univariate logistic regression analysis was carried out to detect potential factors related to clinical outcomes. $\mathrm{P}<0.05$ was considered statistically significant.

\section{Results}

\section{Study identification and selection}

The electronic search strategy yielded 1,174 records, of which 777 were excluded either due to duplication or off-topic after screening title and abstract. Further 69 articles were excluded because they were reviews or had no outcomes of interest. Nineteen eligible studies $(2,9-26)$ were included and the details are summarized in Table S1. The flow gram of identification of the eligible studies is presented in Figure 1.

\section{Characteristic of patients}

Baseline demographics of patients with tigecycline treatment are showed in Table 1. A total of 19 studies involving 31 patients reported cUTI treated with tigecycline. Median age of patients was 61.5 years
Table 1 Baseline characteristics of the included patients

\begin{tabular}{|c|c|c|}
\hline Variables & Number & Values \\
\hline Age (years) & 28 & $\begin{array}{c}61.5 \\
\text { (IQR: 51.5-68. 5) }\end{array}$ \\
\hline Gender, n (\%) & 24 & \\
\hline Male & & $12(50)$ \\
\hline Female & & $12(50)$ \\
\hline Region, n (\%) & 31 & \\
\hline North America & & $13(41.94)$ \\
\hline Europe & & $11(35.48)$ \\
\hline Asia & & $5(16.12)$ \\
\hline South America & & $2(6.45)$ \\
\hline Comorbidities, n (\%) & 31 & \\
\hline Transplantation & & $8(25.80)$ \\
\hline Diabetes mellitus & & $7(22.58)$ \\
\hline Urinary catheter & & $6(19.35)$ \\
\hline ESRD & & $4(12.90)$ \\
\hline Prostatitis and kidney stones & & $4(12.90)$ \\
\hline Surgery and trauma & & $3(9.68)$ \\
\hline Pulmonary disease & & $2(6.45)$ \\
\hline Sepsis, n (\%) & 23 & $13(56.52)$ \\
\hline Causative pathogen, $\mathrm{n}(\%)$ & 29 & \\
\hline K. pneumoniae & & $14(48.28)$ \\
\hline Acinetobacter & & $7(24.14)$ \\
\hline ESBL E. coli & & $6(20.69)$ \\
\hline Myroides odoratimimus & & $2(6.90)$ \\
\hline VRE & & $1(3.45)$ \\
\hline MDR E.aerogenes & & $1(3.45)$ \\
\hline Prior antibiotic therapy, $\mathrm{n}(\%)$ & 15 & \\
\hline None & & $4(26.67)$ \\
\hline$\beta$-lactam antibiotics & & $10(66.67)$ \\
\hline Polymyxin B + tigecycline & & $1(6.67)$ \\
\hline
\end{tabular}

IQR, interquartile range; ESRD, end-stage renal disease; ESBL, extended-spectrum beta-lactamase; VRE, vancomycin resistant Enterococcus; MDR, multiple drug resistance.

[interquartile range (IQR) 51.5-68.5] and the percentage of female was equal to male. Of the 31 cases identified, $25.8 \%$ of patients had comorbidities of transplantation and $22.58 \%$ had diabetes mellitus. Sepsis $(56.52 \%, \mathrm{n}=13)$ was featured 
Table 2 Treatments of tigecycline

\begin{tabular}{|c|c|c|}
\hline Variables & Number & Values \\
\hline $\begin{array}{l}\text { Dose of tigecycline treatment, } \\
n(\%)\end{array}$ & 23 & \\
\hline Standard $(100 \mathrm{mg} / \mathrm{d})$ & & $15(65.22)$ \\
\hline $\begin{array}{l}\text { Higher than standard dose } \\
(200 \mathrm{mg} / \mathrm{d})\end{array}$ & & $7(30.43)$ \\
\hline $\begin{array}{l}\text { Lower than standard dose } \\
(50 \mathrm{mg} / \mathrm{d})\end{array}$ & & $1(4.35)$ \\
\hline $\begin{array}{l}\text { Duration of tigecycline } \\
\text { treatment (days) }\end{array}$ & 28 & 14, IQR (11 to 17$)$ \\
\hline$\leq 7$ & & $3(10.71)$ \\
\hline $7-14$ & & $16(57.14)$ \\
\hline $15-21$ & & $3(10.17)$ \\
\hline$>21$ & & $5(17.86)$ \\
\hline Concomitant antibiotics, n (\%) & 28 & \\
\hline None & & $18(64.29)$ \\
\hline Carbapenems & & $4(14.29)$ \\
\hline Colistin & & $3(10.71)$ \\
\hline Piperacillin/tazobactam & & $2(7.14)$ \\
\hline Fluconazole & & $1(3.57)$ \\
\hline $\begin{array}{l}\text { Total duration of follow-up } \\
\text { (days) }\end{array}$ & 18 & 34, IQR (21 to 120$)$ \\
\hline
\end{tabular}

$I Q R$, interquartile range.

prominently amongst the cases with detailed description of sepsis. The information of pathogens was obtained in 29 cases. Common causative pathogens including Klebsiella pneumoniae (K. pneumoniae) (48.28\%), Acinetobacter spp. (24.14\%) and ESBL positive Escherichia coli (20.69\%) were frequently observed and other pathogens such as Myroides odoratimimus were extremely rare. In 15 cases provided the information of prior antibiotic therapy, a significant group of patients were treated with $\beta$-lactam antibiotics previously $(66.67 \%, \mathrm{n}=10)$ or without prior antibiotic therapy $(26.67 \%$, $\mathrm{n}=4)$.

\section{Treatment}

Details of tigecycline treatments are shown in Table 2. Dosage of tigecycline were available in 23 cases, the vast majority of cases used tigecycline $100 \mathrm{mg} / \mathrm{d}$ as a standard dose $(65.22 \%, \mathrm{n}=15)$, and high-dose tigecycline $(200 \mathrm{mg} / \mathrm{d})$ or low-dose tigecycline $(50 \mathrm{mg} / \mathrm{d})$ was also reported in a few cases. Duration and detailed antibiotic agent of tigecycline treatment were clear in 28 cases, the median duration was 14 days (IQR 11-17) and the duration between 7-14 days was found in most patients (57.14\%), a majority of cases used tigecycline as monotherapy for cUTI $(64.29 \%$, $\mathrm{n}=18)$, while carbapenems $(14.29 \%)$, colistin $(10.71 \%)$, piperacillin/tazobactam (7.14\%) and fluconazole (3.17\%) were used as a concomitant therapy with tigecycline in other reports. Median follow-up of all patients was 34 days (IQR 21-129) among the 18 available cases.

\section{Outcomes}

In terms of detailed outcomes, 24 cases were defined clinical cure account for $77.42 \%(\mathrm{n}=24)$ as a majority in all 31 cases. Recurrence of cUTI was reported in some patients $(36.36 \%, n=4)$ among the 11 cases with detailed outcomes of follow-up. Among the clinical cure cases, patients defined microbiological positive accounted for the vast majority $(65.2 \%)$, only a few cases reserved pathogenic bacteria $(8.33 \%)$ (Figure 2). Two cases reported as clinical failure but showed microbiological positive result, because both patients died but the death were not related to tigecycline treatment and their urinary tract pathogen culture were defined as microbiological positive.

\section{Factors predicting clinical outcome}

The correlation between clinical cure and influence factors such as age, gender and others were analyzed by univariate logistic regression analysis. Univariate analysis showed that pathogen $K$. pneumoniae might be the risk factor of clinical failure, and tigecycline monotherapy was related to clinical cure $(\mathrm{P}<0.1)$. The details of factors analyses were described in Table 3.

\section{Discussion}

\section{Major findings and interpretations}

Our findings drew the detailed information for the effectiveness and safety of tigecycline treatment for cUTI based on 31 cases in 19 articles. The results demonstrated tigecycline has a favorable clinical response in cUTI, and in the patients who was confirmed clinical cure, vast majority observed bacteria eradication in urine culture with no recurrence. Univariate logistical analysis suggested that 


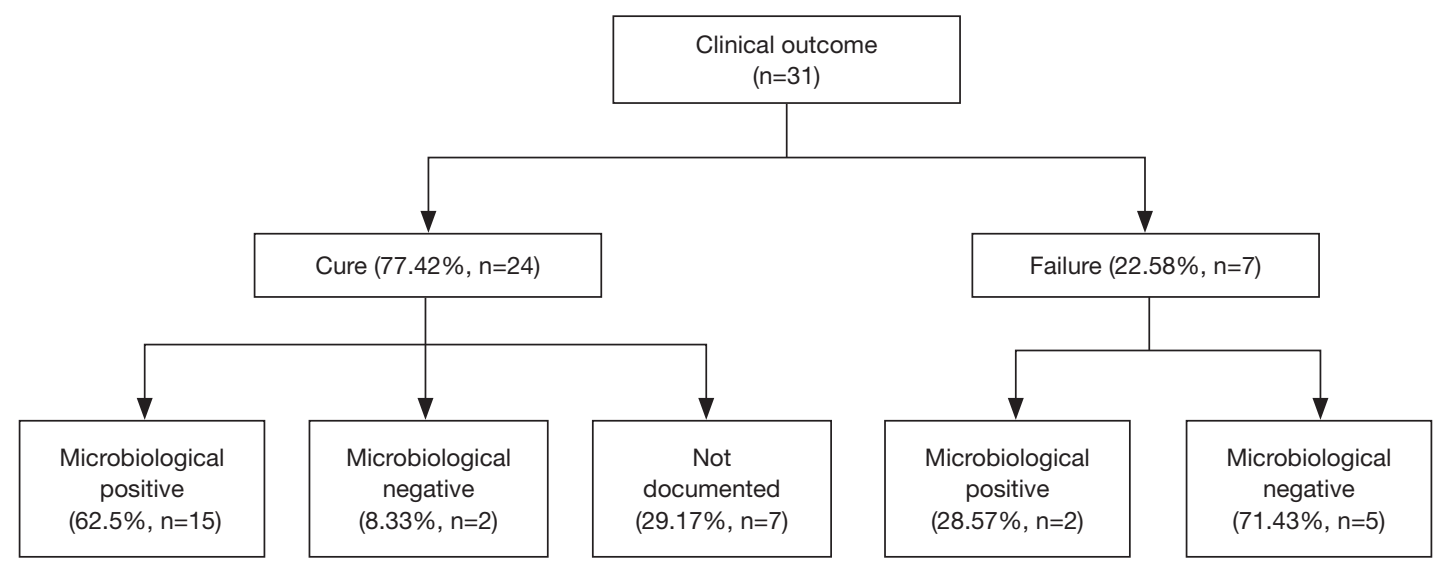

Figure 2 Flow diagram of outcome. The clinical and microbiological outcome of 31 cases in 19 articles.

Table 3 Univariate logistic regression analysis of clinical outcomes

\begin{tabular}{|c|c|c|}
\hline \multirow{2}{*}{ Variables } & \multicolumn{2}{|c|}{ Univariate analysis } \\
\hline & $P$ value & OR $(95 \% \mathrm{Cl})$ \\
\hline Age & 0.12 & $0.94(0.87-1.02)$ \\
\hline Gender & 0.62 & $1.67(0.23-12.35)$ \\
\hline \multicolumn{3}{|l|}{ Risk factors/etiology } \\
\hline Transplantation & 0.42 & $0.48(0.08-2.92)$ \\
\hline Diabetes mellitus & 0.91 & $0.89(0.13-6.16)$ \\
\hline Urinary catheter & 0.69 & $0.67(0.09-4.81)$ \\
\hline ESRD & 0.93 & $1.13(0.10-13.04)$ \\
\hline Sepsis & 0.25 & $0.25(0.02-2.70)$ \\
\hline \multicolumn{3}{|l|}{ Causative pathogen } \\
\hline K. pneumoniae & 0.04 & $0.95(0.01-0.94)$ \\
\hline Acinetobacter & 0.49 & $2.25(0.22-22.80)$ \\
\hline \multicolumn{3}{|l|}{ Dose of tigecycline } \\
\hline Standard $(100 \mathrm{mg} / \mathrm{d})$ & 0.65 & $0.57(0.05-6.61)$ \\
\hline High (200 mg/d) & 0.80 & $1.39(0.12-16.23)$ \\
\hline Duration of tigecycline & 0.54 & $1.04(0.93-1.16)$ \\
\hline \multicolumn{3}{|l|}{ Concomitant antibiotics } \\
\hline None & 0.03 & $8.00(1.17-54.72)$ \\
\hline Carbapenems & 0.23 & $0.26(0.03-2.24)$ \\
\hline Colistin & 0.73 & $0.63(0.05-8.25)$ \\
\hline
\end{tabular}

OR, odds ratio; ESRD, end-stage renal disease.

tigecycline failed in treatment of $K$. pneumoniae caused cUTI even with increased dose, and tigecycline monotherapy achieved better clinical results. It was especially remarkable given the fact that tigecycline was not recommend for
K. pneumoniae caused cUTI. Despite these concerns, tigecycline monotherapy was still considered alternative for treating cUTI when other options are limited.

\section{Comparison with previous studies}

Tigecycline is a derivative of minocycline which attracted clinicians attention because of its excellent in vitro activity against most gram-negative pathogens and relatively mild adverse effects (2). Numerous studies have suggested tigecycline in the treatment of infections caused by MDR organisms, especially Acinetobacter baumannii and carbapenemase producing Enterobacteriaceae (5). However, although tigecycline has high rates of in vitro susceptibility to MDR, the package insert of tigecycline states that $33 \%$ of a dose is excreted in urine, and tigecycline has a much greater volume of distribution than most other antimicrobials which can achieve $7-10 \mathrm{~L} / \mathrm{kg}$ (20). These findings generally doubted that tigecycline is a viable option for cUTI because tigecycline has limited excretion into lower urinary system (27). Meanwhile, the previous studies published have demonstrated inconsistent results. In a study by Satlin et al., tigecycline achieved microbiological clearance and better clinical outcomes in patients with cUTI (8). In addition, high-dose tigecycline regimen of 200 $\mathrm{mg}$ was administered to patients with UTI caused by $K$. pneumoniae in several reports (6), and the microbiological clearances were achieved. However, most studies were case reports that positive results observed may attributed to publication bias and has not been validated in a systematically evaluated study.

Our study evaluated tigecycline for cUTI from a number 
of heterogenous patients and the results suggested that tigecycline may be a viable therapeutic option for cUTI. In our study, tigecycline had a higher success rate in clinical and microbiological outcomes and dosage was not a factor affecting the outcomes through logistic regression analysis.

\section{Potential mechanism}

A possible explanation of success in cUTI treatment of tigecycline could be that pathogens causing cUTI were various and tigecycline had a broad antimicrobial spectrum covering both gram-positive and gram-negative bacteria. Furthermore, as a relatively new glycylcycine, highly resistant gram-negative bacteria (including ESBL or CRE) might be sensitive to tigecycline even at low concentration. Above speculation provide a possible explanation of successful use of tigecycline for cUTI. The results by univariate analyses showed that the rate of pathogen $K$. pneumoniae was significantly high in the failure group. Although tigecycline showed high antimicrobial activity against a broad spectrum of pathogens among which most pathogens were resistant to other antibiotics, the clinical efficacy of tigecycline was most closely related to AUC/MIC ratio. In a study by Nicasio et al. (28), the free $\mathrm{AUC}_{24} / \mathrm{MIC}$ ratio against strains of $K$. pneumoniae needed to achieve adequate bacterial killing was between 1.3 and 1.8 which can be achieved in serum with standard dose. However, this effective concentration was not reached with excreted $33 \%$ of a dose in urine.

\section{Clinical consideration}

Urinary tract is a common site of infection and cUTI can involve any age group, especially in patients with functional or structural abnormality of the urinary tract (6). With increasing bacterial resistance and the slower pace of antimicrobial development, the regimens for cUTI is gradually decreasing, and there is very little published literature on cUTI due to MDR organisms and other rare pathogens (29). The finding is important for clinical practice because our study added to the accumulating data that tigecycline regimen demonstrated a relatively good clinical response on cUTI and provided a possible option for limited clinical treatment for cUTI. Adverse events possibly associated with tigecycline were not observed in most cases, but there still might be a risk of tigecycline such as diarrhea, neutrophil engraftment delay (7). Therefore, tigecycline must be administrated according to results of pathogen culture and adverse effects should be monitored adequately during tigecycline treatment process.

\section{Limitations}

There are inherent limitations in this study. Firstly, the small sample size limited the availability of epidemiologic data and outpatient could not be adequately evaluated with this design. Secondly, although our article described that tigecycline treatment for cUTI had a better clinical outcome, there was a potential publication bias as authors may not reported cUTI that were treated with tigecycline with unsuccessful treatment outcome. In addition, some valid cases might be excluded because the language restrictions. And this meta-summary was a retrospective design of case report to evaluate the presented management strategy, which required more data from large real-world registries or randomized control trials.

\section{Conclusions}

Based on our study, the use of tigecycline in cUTI achieved favored clinical and microbiological outcomes. However, if the cUTI was caused by $K$. pneumoniae, tigecycline might not be a good choice. In addition, a majority of data from our review showed no clear adverse effects caused by tigecycline. Thus, tigecycline can be considered when target pathogen and well-established safety monitoring system are available.

\section{Acknowledgments}

Funding: This study was funded by Clinical Pharmacy Innovation Research Institute of Shanghai Jiao Tong University School of Medicine (CXYJY2019ZD001, CXYJY2019QN004), Research Funds of Shanghai Health and Family Planning commission (20184Y0022, 20194Y0007), WU JIEPING medical foundation (320.6750.2020-04-31), Cultivation fund of clinical research of Renji hospital (PY2018-III-06), and Program for Key but Weak Disciplines of Shanghai Municipal Commission of Health and Family Planning (2016ZB0304).

\section{Footnote}

Reporting Checklist: The authors have completed the PRISMA reporting checklist. Available at http://dx.doi. org/10.21037/tau-20-959 
Peer Review File: Available at http://dx.doi.org/10.21037/ tau-20-959

Conflicts of Interest: All authors have completed the ICMJE uniform disclosure form (available at http://dx.doi. org/10.21037/tau-20-959). The authors have no conflicts of interest to declare.

Ethical Statement: The authors are accountable for all aspects of the work in ensuring that questions related to the accuracy or integrity of any part of the work are appropriately investigated and resolved. The ethical approval and consent are not required because no patientlevel data is involved for this systematic review.

Open Access Statement: This is an Open Access article distributed in accordance with the Creative Commons Attribution-NonCommercial-NoDerivs 4.0 International License (CC BY-NC-ND 4.0), which permits the noncommercial replication and distribution of the article with the strict proviso that no changes or edits are made and the original work is properly cited (including links to both the formal publication through the relevant DOI and the license). See: https://creativecommons.org/licenses/by-nc-nd/4.0/.

\section{References}

1. Rodrigues dos Santos BG, Amaral ES, Fernandes PFCBC, et al. Urinary Tract Infections and Surgical Site Infections due to Carbapenem-Resistant Enterobacteriaceae in Renal Transplant. Transplant Proc 2016;48:2050-5.

2. Brust K, Evans A, Plemmons R. Tigecycline in treatment of multidrug-resistant Gram-negative bacillus urinary tract infections: A systematic review. J Antimicrob Chemother 2014;69:2606-10.

3. Tasina E, Haidich AB, Kokkali S, et al. Efficacy and safety of tigecycline for the treatment of infectious diseases: a meta-analysis. Lancet Infect Dis 2011;11:834-44.

4. Tsuji BT, Pogue JM, Zavascki AP, et al. International Consensus Guidelines for the Optimal Use of the Polymyxins: Endorsed by the American College of Clinical Pharmacy (ACCP), European Society of Clinical Microbiology and Infectious Diseases (ESCMID), Infectious Diseases Society of America (IDSA), International Society for Anti-infective Pharmacology (ISAP), Society of Critical Care Medicine (SCCM), and Society of Infectious Diseases Pharmacists (SIDP). Pharmacotherapy 2019;39:10-39.
5. Meagher AK, Ambrose PG, Grasela TH, et al. The pharmacokinetic and pharmacodynamic profile of tigecycline. Clin Infect Dis 2005;41 Suppl 5:S333-40.

6. Wu G, Abraham T, Saad N. Role of tigecycline for the treatment of urinary tract infections. J Pharm Technol 2014;30:87-92.

7. Temocin F, Tülek NE, Hekimoğlu Ş, et al. Five-years tigecycline experience an analysis of real-life data. Haseki Tip Bulteni 2018;56:125-30.

8. Satlin MJ, Kubin CJ, Blumenthal JS, et al. Comparative effectiveness of aminoglycosides, polymyxin $\mathrm{B}$, and tigecycline for clearance of carbapenem-resistant Klebsiella pneumoniae from urine. Antimicrob Agents Chemother 2011;55:5893-9.

9. Cunha BA, McDermott B, Nausheen S. Single daily high-dose tigecycline therapy of a multidrug-resistant (MDR) Klebsiella pneumoniae and Enterobacter aerogenes nosocomial urinary tract infection. J Chemother 2007;19:753-4.

10. Reid GE, Grim SA, Aldeza CA, et al. Rapid development of Acinetobacter baumannii resistance to tigecycline. Pharmacotherapy 2007;27:1198-201.

11. Anthony KB, Fishman NO, Linkin DR, et al. Clinical and microbiological outcomes of serious infections with multidrug-resistant gram-negative organisms treated with tigecycline. Clin Infect Dis 2008;46:567-70.

12. Gallagher JC, Rouse HM. Tigecycline for the treatment of Acinetobacter infections: A case series. Ann Pharmacother 2008;42:1188-94.

13. Krueger WA, Kempf VA, Peiffer M, et al. Treatment with tigecycline of recurrent urosepsis caused by extendedspectrum-beta-lactamase-producing Escherichia coli. J Clin Microbiol 2008;46:817-20.

14. Elemam A, Rahimian J, Mandell W. Infection with panresistant Klebsiella pneumoniae: a report of 2 cases and a brief review of the literature. Clin Infect Dis 2009;49:271-4.

15. Weisenberg SA, Morgan DJ, Espinal-Witter R, et al. Clinical outcomes of patients with Klebsiella pneumoniae carbapenemase-producing K. pneumoniae after treatment with imipenem or meropenem. Diagn Microbiol Infect Dis 2009;64:233-5.

16. Geerlings SE, van Donselaarvan der Pant KAMI, Keur I. Successful treatment with tigecycline of two patients with complicated urinary tract infections caused by extendedspectrum $\beta$-lactamase-producing Escherichia coli. J Antimicrob Chemother 2010;65:2048-9.

17. Drekonja DM, Johnson JR. Tigecycline treatment for 
urinary tract infections: Case report and literature review. J Chemother 2011;23:168-70.

18. Kuo SC, Wang FD, Fung CP, et al. Clinical experience with tigecycline as treatment for serious infections in elderly and critically ill patients. J Microbiol Immunol Infect 2011;44:45-51.

19. Solak Y, Atalay H, Turkmen K, et al. Community-acquired carbapenem-resistant Acinetobacter baumannii urinary tract infection just after marriage in a renal transplant recipient. Transpl Infect Dis 2011;13:638-40.

20. Bates D, Parkins M, Hellweg R, et al. Tigecycline treatment of urinary tract infection and prostatitis: Case report and literature review. Can J Hosp Pharm 2012;65:209-15.

21. Tsai HY, Liao CH, Cheng A, et al. Emergence of tigecycline-resistant Klebsiella pneumoniae after tigecycline therapy for complicated urinary tract infection caused by carbapenem-resistant Escherichia coli. J Infect 2012;65:584-6.

22. Cicora F, Mos F, Paz M, et al. Infections with blaKPC2-producing Klebsiella pneumoniae in renal transplant patients: A retrospective study. Transplant Proc 2013;45:3389-93.

23. Balandin Moreno B, Fernandez Simon I, Pintado Garcia V, et al. Tigecycline therapy for infections due to carbapenemase-producing Klebsiella pneumoniae in

Cite this article as: Liu YX, Le KJ, Shi HY, Zhang ZL, Cui M, Zhong H, Yu YT, Gu ZC. Efficacy and safety of tigecycline for complicated urinary tract infection: a systematic review. Transl Androl Urol 2021;10(1):292-299. doi: 10.21037/tau-20-959 critically ill patients. Scand J Infect Dis 2014;46:175-80.

24. Mouloudi E, Massa E, Piperidou M, et al. Tigecycline for treatment of carbapenem-resistant klebsiella pneumoniae infections after liver transplantation in the intensive care unit: A 3-year study. Transplant Proc 2014;46:3219-21.

25. Lee CT, Chu HM, Chang CL. Is tigecycline prescribed to treat carbapenem-resistant acinetobacter baumannii complicated urinary tract infections. J Microbiol Immunol Infect 2015;48:S137.

26. Licker M, Sorescu T, Rus M, et al. Extensively drugresistant Myroides odoratimimus - A case series of urinary tract infections in immunocompromised patients. Infect Drug Resist 2018;11:743-9.

27. Castanheira M, Sader HS, Jones RN. Antimicrobial susceptibility patterns of KPC-producing or CTX-Mproducing Enterobacteriaceae. Microb Drug Resist 2010;16:61-5.

28. Nicasio AM, Crandon JL, Nicolau DP. In vivo pharmacodynamic profile of tigecycline against phenotypically diverse Escherichia coli and Klebsiella pneumoniae isolates. Antimicrob Agents Chemother 2009;53:2756-61.

29. Alexander BT, Marschall J, Tibbetts RJ, et al. Treatment and Clinical Outcomes of Urinary Tract Infections Caused by KPC-Producing Enterobacteriaceae in a Retrospective Cohort. Clin Ther 2012;34:1314-23. 
Table S1 Details of 31 patients treated with tigecycline in 19 literature for cUTI

\begin{tabular}{|c|c|c|c|c|c|c|c|c|c|c|c|c|c|}
\hline \multirow{2}{*}{ Patient No. } & \multirow{2}{*}{ Age, years } & \multirow{2}{*}{ Sex } & \multirow{2}{*}{ Risk factors } & \multirow{2}{*}{ Sepsis } & \multirow{2}{*}{$\begin{array}{l}\text { Causative } \\
\text { pathogen }\end{array}$} & \multirow{2}{*}{ Prior antibiotic therapy } & \multicolumn{3}{|c|}{ Tigecycline regimen } & \multicolumn{2}{|c|}{ Response } & \multirow{2}{*}{ Relapse } & \multirow{2}{*}{ Follow-up } \\
\hline & & & & & & & Dose & Duration & Concomitant & Clinical & Microbiologic & & \\
\hline \multirow[t]{2}{*}{1 (2) } & 54 & $\mathrm{~F}$ & DM & NS & MDR AB & NS & $100 \mathrm{mg}$ q12h & 17 days & None & Cure & Positive & NS & 6 weeks \\
\hline & 64 & M & DM & NS & $\begin{array}{l}\text { ESBL } K . \\
\text { pneumoniae }\end{array}$ & NS & $100 \mathrm{mg}$ q12h & 11 days & None & Failure & Positive & Died & 6 weeks \\
\hline $2(9)$ & NS & M & Urinary catheter & NS & $\begin{array}{l}\text { MDR } K \text {. } \\
\text { pneumoniae } \mathrm{E} . \\
\text { aerogenes }\end{array}$ & NS & $200 \mathrm{mg}$ q24h & 12 days & None & Cure & Positive & NS & 12 days \\
\hline $3(10)$ & 53 & $\mathrm{~F}$ & Kidney and liver transplantation, urinary catheter & NS & MDR AB and VRE & LVX, P/T, VAN & $100 \mathrm{mg} \mathrm{q12h}$ & 14 days & None & Cure & Positive & Yes & 3 months \\
\hline $4(11)$ & 25 & $\mathrm{~F}$ & $\begin{array}{l}\text { chronic urinary reflux, lumbar meningomyelocele } \\
\text { and paraparesis below the second lumbar } \\
\text { segment }\end{array}$ & Yes & ESBLE. coli & $\begin{array}{l}\text { LVX, P/T, CTX, AMK, } \\
\text { MEM, LNZ, voriconazole }\end{array}$ & NS & 13 days & None & Cure & Positive & NS & 38 days \\
\hline \multirow[t]{3}{*}{5 (12) } & 63 & NS & NS & NS & NS & NS & $100 \mathrm{mg} \mathrm{q} 12 \mathrm{~h}$ & 4 days & None & Cure & Positive & NS & 30 days (range, 3-89) \\
\hline & 49 & NS & NS & NS & NS & NS & $100 \mathrm{mg}$ q12h & 13 days & None & Cure & Positive & NS & 30 days (range, 3-89) \\
\hline & 63 & NS & NS & NS & Acinetobacter & NS & $100 \mathrm{mg}$ q12h & 12 days & Col & Cure & Positive & NS & 30 days (range, 3-89) \\
\hline $6(13)$ & 70 & $\mathrm{~F}$ & Pneumonia, urinary catheter & NS & $\begin{array}{l}\text { PDR } K . \\
\text { pneumoniae }\end{array}$ & Tigecycline, PMB & NS & 10 days & Rifampin & Failure & Negative & Yes & 1 year \\
\hline 7 (14) & 39 & $\mathrm{~F}$ & Stem cell transplant & Yes & K. pneumoniae & IMI & $100 \mathrm{mg} \mathrm{q} 12 \mathrm{~h}$ & 14 days & None & Cure & NS & NS & 3 weeks \\
\hline \multirow[t]{2}{*}{$8(15)$} & 67 & M & Polyneuropathy & Yes & K. pneumoniae & IMI & $100 \mathrm{mg} \mathrm{q12h}$ & 7 days & None & Failure & Negative & NS & 3 weeks \\
\hline & 44 & M & Renal transplant, DM, chronic prostatitis & NS & ESBLE. coli & MEM & NS & 42 days & None & Cure & Positive & NO & 18 weeks, 5 months \\
\hline 9 (16) & 66 & $\mathrm{~F}$ & ESRD & NS & ESBL E. coli & NS & NS & 42 days & None & Cure & Positive & NO & 6 weeks, 4 months \\
\hline $10(17)$ & 27 & $\mathrm{~F}$ & Renal transplant & Yes & MDR AB & IMI & $50 \mathrm{mg} / \mathrm{d}$ & NS & None & Cure & Positive & NS & NS \\
\hline $11(18)$ & 76 & M & $\begin{array}{l}\text { Spinal stenosis, lumbar osteomyelitis with epidural } \\
\text { abscess, CKD }\end{array}$ & Yes & MDR AB & NS & $100 \mathrm{mg}$ q $12 \mathrm{~h}$ & 12 days & $\begin{array}{l}\mathrm{P} / \mathrm{T}, \mathrm{IMI}, \\
\text { sulbactam }\end{array}$ & Failure & Negative & NS & 19 days \\
\hline 12 (19) & 70 & $\mathrm{~F}$ & Polymyositis, interstitial lung disease & NO & ESBLE. coli & CEL, CFM, LVX & $100 \mathrm{mg} / \mathrm{d}$ & $\begin{array}{l}14 \text { days, } 7 \\
\text { days }\end{array}$ & None & Cure & Positive & NS & 3 weeks \\
\hline $13(20)$ & 86 & M & CKD, DM, HTN, prostatic hypertrophy & Yes & ESBLE. coli & CTX, P/T, MEM, ETP & $100 \mathrm{mg} \mathrm{q} 12 \mathrm{~h}$ & $\begin{array}{l}25 \text { days, } 42 \\
\text { days }\end{array}$ & Fluconazole & Cure & Negative & NO & 157 days \\
\hline \multirow[t]{2}{*}{$14(21)$} & 71 & NS & Renal transplant, DM, urinary catheter & Yes & $\begin{array}{l}\text { blakPC-2- } \\
\text { Producing } K \text {. } \\
\text { pneumoniae }\end{array}$ & None & NS & $\begin{array}{l}21 \text { days, } 16 \\
\text { days }\end{array}$ & CST & Failure & Negative & Yes & NS \\
\hline & 50 & NS & Renal transplant & None & $\begin{array}{l}\text { blaKPC-2- } \\
\text { Producing } K \text {. } \\
\text { pneumoniae }\end{array}$ & None & NS & $\begin{array}{l}26 \text { days, } 21 \\
\text { days }\end{array}$ & MEM & Failure & Negative & Yes & NS \\
\hline \multirow[t]{5}{*}{$15(22)$} & 65 & $\mathrm{~F}$ & Bone marrow transplantation & Yes & CRKP & NS & $200 \mathrm{mg} / \mathrm{d}$ & 11 days & $\mathrm{P} / \mathrm{T}$ & Failure & Positive & NS & NS \\
\hline & 60 & $\mathrm{~F}$ & Cardiac surgery & Yes & CRKP & NS & $200 \mathrm{mg} / \mathrm{d}$ & 6 days & IMI & Cure & NS & NS & NS \\
\hline & 34 & M & Multiple trauma & Yes & CRKP & NS & $200 \mathrm{mg} / \mathrm{d}$ & 8 days & None & Cure & NS & NS & NS \\
\hline & 80 & M & Ulcerative colitis, abdominal surgery & Yes & CRKP & NS & $200 \mathrm{mg} / \mathrm{d}$ & 9 days & None & Cure & Negative & NS & NS \\
\hline & 54 & M & Non-Hodgkin Iymphoma & Yes & CRKP & NS & $100 \mathrm{mg} / \mathrm{d}$ & 15 days & MEM & Cure & Positive & NS & NS \\
\hline $16(23)$ & 53 & $\mathrm{~F}$ & $\begin{array}{l}\text { DM, stage } 3 \text { CKD, nephrolithiasis, right double-J } \\
\text { ureteral stent }\end{array}$ & None & CRKP & VAN, P/T & $\begin{array}{c}200 \mathrm{mg}, 100 \mathrm{mg} \text { q12h, then } \\
200 \mathrm{mg} \mathrm{q} 24 \mathrm{~h} \text {, then } 100 \mathrm{mg} \\
\text { q12h }\end{array}$ & 17 days & & Cure & Positive & None & 14 \\
\hline \multirow[t]{2}{*}{$18(25)$} & NS & NS & NS & None & CRAB & NS & $50 \mathrm{mg} \mathrm{q} 12 \mathrm{~h}$ & 14 days & NS & Cure & NS & NS & NS \\
\hline & NS & NS & NS & None & CRAB & NS & $100 \mathrm{mg} \mathrm{q} 12 \mathrm{~h}$ & 14 days & NS & Cure & NS & NS & NS \\
\hline \multirow[t]{2}{*}{19 (26) } & 59 & $\mathrm{~F}$ & DM, PAD, HTN, Urethro-vesical catheterization & None & $\begin{array}{l}\text { Myroides } \\
\text { odoratimimus }\end{array}$ & None & NS & NS & None & Cure & NS & NS & NS \\
\hline & 72 & M & $\mathrm{BPH}, \mathrm{COPD}$ & None & $\begin{array}{l}\text { Myroides } \\
\text { odoratimimus }\end{array}$ & None & NS & NS & None & Cure & NS & NS & NS \\
\hline
\end{tabular}

